\title{
Global Quantitative Sensitivity Analysis and Compensation of Geometric Errors of CNC Machine Tool
}

\author{
Shijie Guo, Dongsheng Zhang, and Yang Xi \\ School of Mechanical Engineering, State Key Laboratory for Manufacturing Systems Engineering, Xian Jiaotong University, \\ Xian 710049, China \\ Correspondence should be addressed to Dongsheng Zhang; zdsxjtul1974@gmail.com
}

Received 8 January 2016; Revised 5 March 2016; Accepted 23 March 2016

Academic Editor: Yan-Jun Liu

Copyright (C) 2016 Shijie Guo et al. This is an open access article distributed under the Creative Commons Attribution License, which permits unrestricted use, distribution, and reproduction in any medium, provided the original work is properly cited.

\begin{abstract}
A quantitative analysis to identify the key geometric error elements and their coupling is the prerequisite and foundation for improving the precision of machine tools. The purpose of this paper is to identify key geometric error elements and compensate for geometric errors accordingly. The geometric error model of three-axis machine tool is built on the basis of multibody system theory; and the quantitative global sensitivity analysis (GSA) model of geometric error elements is constructed by using extended Fourier amplitude sensitivity test method. The crucial geometric errors are identified; and stochastic characteristics of geometric errors are taken into consideration in the formulation of building up the compensation strategy. The validity of geometric error compensation based on sensitivity analysis is verified on a high-precision three-axis machine tool with open CNC system. The experimental results show that the average compensation rates along the $X, Y$, and $Z$ directions are $59.8 \%, 65.5 \%$, and $73.5 \%$, respectively. The methods of sensitivity analysis and geometric errors compensation presented in this paper are suitable for identifying the key geometric errors and improving the precision of CNC machine tools effectively.
\end{abstract}

\section{Introduction}

With the rapid development of modern manufacturing technology, higher precision of CNC machine tools is required. The precision of machine tools has much concern at their design stage and operation processes. The factors affecting the precision of CNC machine tools include geometric errors, thermally induced errors, cutting force deformation errors, kinematic errors, and fixture-dependent errors [1]. Among these error sources, the geometric errors and kinematic errors are the major ones, which are defined as quasistatic errors [2]. They are time-varying and related to the structure of machine tools. Geometric errors account for more than 50\% of the total error in machine tools [3], mainly due to the manufacturing and installation of machine tools.

The effective control of geometric errors is critically important for enhancing the machining accuracy of machine tools. There are two ways to eliminate the geometric errors, that is, error avoidance and error compensation [1]. The error avoidance is focused on how to control the precision to a maximum through the precision design, manufacturing, and installation; and error compensation is realized by using the special measuring instruments to identify and eliminate geometric errors. The identification of critical geometric error elements and coupling effect is key technology for designing, assembling, and error compensation.

The error modeling is a prerequisite to identify the dominant contributors to the overall error of machine tools. In the past decades, the error models describing the function and rela tionship of geometric errors of multiaxis CNC machine tools have been well established [4, 5]. Eman et al. [6] applied Denavit-Hartenberg (D-H) method to build a generalized error model for multiaxis machine tool with arbitrary configuration. Schultschik [7] proposed vector chain expression method for establishing the volumetric error model of a three-axis machine tool. Chen et al. [8] presented a comprehensive error model of three-axis CNC machine tool on the assumption of nonrigid body. Kiridena and Ferreira [9] described the coordinate transformation between adjacent components by using $\mathrm{D}-\mathrm{H}$ method and established the error models for three types of five-axis machine tools (TTTRR type, RTTTR type, and RRTTT 
type). Yang et al. [10] proposed a quadratic model of a horizontal machining center, which includes the geometric errors and thermal errors. Lin and Shen [11] applied the matrix summation method instead of matrix product to develop the geometric error model of five-axis machine tools. Sencer et al. [12] proposed a contour error model for a fiveaxis machine tool; and the error compensation was realized by sliding mode control. Liu et al. [13] proposed fuzzy optimal control design for classic nonlinear discrete-time systems with backlash. Based on the screw theory, Yang et al. [14] proposed a new model to describe the rigid body motion of the machine drives; and the position-independent geometric errors were identified through double ball bar (DBB) tests. Fu et al. [15] established an exponent product model for multiaxis machine tools; and the experiments have been conducted to verify the model. An observer-based adaptive fuzzy controller was developed for nonlinear discrete-time systems; a fine stability in control systems has been obtained and the tracking error fluctuated within a narrow range [16]. Among these methods, the modeling approach-based Multibody System (MBS) theory [17, 18] can express the motion relationship among the components of multiaxis machine tools. Therefore, HTMs method and MBS theory were adopted to establish the geometric errors model in this study.

Sensitivity analysis is used to determine the effects of changes in input parameters on the output parameters. In this research, sensitivity analysis was used to study the influence of geometric error elements (input parameters) on the volumetric error vector (output parameter) and identify the key errors of machine tools. Sensitivity analysis can be classified into local sensitivity analysis (LSA) and global sensitivity analysis (GSA) [19]. LSA methods (Manual Differentiation method, Symbolic Differentiation method, Complex Variables method, Analytical method, etc.) analyze the effect of a small change in each input parameter on output parameters; and GSA methods study the effect of simultaneous arbitrary variations of multiple parameters [20]. Geometric errors exist in machine tools, and different geometric error elements have couplings, which may affect the volumetric errors of machine tools [21]. In this sense, studying the effect of geometric error elements on machine tool's precision is necessary and of great significance. Tsutsumi and Saito [22] studied the effects of eight systematic deviations peculiar to the rotary axes of RRTTT type 5-axis machining centers by simulation and experiment. Huang et al. [23] applied matrix differential method to establish the error mapping function and identify the error source affecting the uncompensable pose error; and the results of this investigation were successfully applied in the machine tool's assembly. Xi et al. [24] analyzed the sensitivity of the inverse Jacobian matrix for optimal calibration of parallel kinematic machines. The discretetime dynamic inversion compensation method [25] has been proposed based on approximating the unknown functions and unknown backlash by the fuzzy logic systems. Lee and Lin [26] used the form-shaping function to establish assembly error model; and the sensitivities of indirect compensation geometric error elements were obtained. Li et al. [27] identified key geometric errors for a three-axis machine tool based on matrix differential method. Cheng et al. [28] introduced Sobol GSA to determine the key affecting factors of threeaxis machine tools. Chen et al. [29] adopted LSA method to study the sensitivity of 37 geometric error elements of a five-axis ultraprecision machine tool; and the analysis results were used in machine tool design and manufacturing. Zhang et al. [30] studied the effect of geometric errors on volumetric error of three-axis machine tool by using the multiplicative dimensional reduction method. Liu and Tong [31] designed an adaptive fuzzy controller for multiinput multioutput systems after considering the effect of unknown interconnection terms. Compared with other sensitivity analysis methods, global sensitivity analysis is more suitable to quantitatively analyze a multiple factor problem [32]. In this study, an extend Fourier amplitude sensitivity test (EFAST) based on variance analysis was introduced for analyzing the key geometric errors and their coupling effect.

Previous studies focused mainly on developing measurement techniques and identification methods for geometric errors of machine tools, but the effects of geometric errors on volumetric errors have rarely been quantitatively analyzed. As a result the application of the GSA of geometric errors in error compensation has seldom been considered. This paper focuses on the identification of critical geometric error elements and error compensation based on EFAST method for three-axis machine tools. The structure of the paper is as follows: in Section 2, geometric error modeling, measurement, and identification are conducted. In Section 3, the GSA model of three-axis machine tools is given based on EFAST method and the identified results of critical factors are described in detail. In Section 4, experiments based on the result of global sensitivity analysis are carried out on three-axis machine tool with open CNC system to testify the precision after error compensation. Some conclusions are drawn finally.

\section{Geometric Error Modeling and Identification for Three-Axis Machine Tools}

2.1. Structure and Error Element Definition of Machine Tool. A three-axis vertical milling machine was taken as the research object, which includes three translational axes and one spindle. The reference coordinate system $\left(O_{R}\right)$ is set on the machine coordinate system; and other local coordinate systems are set on components of the machine tool. Its structural configuration belongs to XYTZ type [33], as depicted in Figure 1.

Known from the nature of rigid body motion, each machine tool component has six degrees of freedom in the Cartesian coordinate system. Geometric errors exist in moving components. Each linear axis has three positional errors (one positioning error and two straightness errors) and three angular errors (yaw error, pitch error, and roll error). For three-axis vertical milling machine, there exist three squareness errors between three linear axes [34]. The 21 geometric errors of three-axis machine tool have been listed in Table 1. 
TABLE 1: Definition of the geometric errors.

\begin{tabular}{lcccc}
\hline Linear axis & Positioning error & Straightness error & Angular error & Squareness error \\
\hline$X$ & $\delta_{x}(x)$ & $\delta_{y}(x), \delta_{z}(x)$ & $\varepsilon_{x}(x), \varepsilon_{y}(x), \varepsilon_{z}(x)$ \\
$Y$ & $\delta_{y}(y)$ & $\delta_{x}(y), \delta_{z}(y)$ & $\varepsilon_{x}(y), \varepsilon_{y}(y), \varepsilon_{z}(y)$ & $S_{x y}, S_{y z}, S_{x z}$ \\
$Z$ & $\delta_{z}(z)$ & $\delta_{x}(z), \delta_{y}(z)$ & $\varepsilon_{x}(z), \varepsilon_{y}(z), \varepsilon_{z}(z)$ \\
\hline
\end{tabular}

$\delta$ and $\varepsilon$ represent translational errors and angle error, respectively; subscript is the error direction and the position coordinate is defined within the parenthesis. $S_{x y}, S_{y z}$, and $S_{x z}$ are squareness errors between each pair of axes.

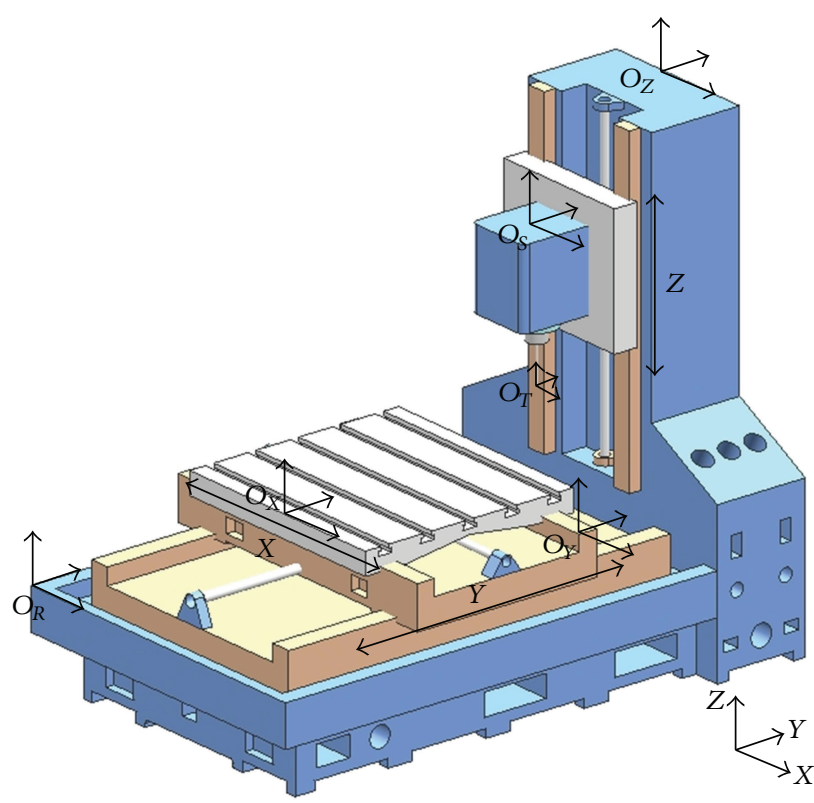

FIGURE 1: The structure diagram of three-axis machine tool.

2.2. Geometric Error Model of a Three-Axis Machine Tool. When the movement distances of linear axis are $x, y$, and $z$ along $X, Y$, and $Z$ directions, respectively, the position relationship of adjacent components can be expressed by using homogeneous transfer matrix, as shown in (1) [17]. $D_{1}$, $D_{2}$, and $D_{3}(200 \mathrm{~mm})$ represent location coordinates of the cutting point with respect to the tool coordinate system in $X$, $Y$, and $Z$ directions, respectively:

$$
\begin{gathered}
{ }_{Y}^{X} \mathbf{T}^{i}=\left[\begin{array}{llll}
1 & 0 & 0 & x \\
0 & 1 & 0 & 0 \\
0 & 0 & 1 & 0 \\
0 & 0 & 0 & 1
\end{array}\right], \\
{ }_{R}^{Y} \mathbf{T}^{i}=\left[\begin{array}{llll}
1 & 0 & 0 & 0 \\
0 & 1 & 0 & y \\
0 & 0 & 1 & 0 \\
0 & 0 & 0 & 1
\end{array}\right],
\end{gathered}
$$

$$
\begin{aligned}
{ }_{Z}^{R} \mathbf{T}^{i} & =\left[\begin{array}{llll}
1 & 0 & 0 & 0 \\
0 & 1 & 0 & 0 \\
0 & 0 & 1 & z \\
0 & 0 & 0 & 1
\end{array}\right], \\
{ }_{T}^{S} \mathbf{T} & =\left[\begin{array}{llll}
1 & 0 & 0 & D_{1} \\
0 & 1 & 0 & D_{2} \\
0 & 0 & 1 & D_{3} \\
0 & 0 & 0 & 1
\end{array}\right],
\end{aligned}
$$

where ${ }_{m}^{n} \mathbf{T}^{i}$ represents the transformational matrix, which is from $m$ coordinate system to $n$ coordinate system under ideal conditions.

There is no relative motion between spindle and $Z$ axis under ideal conditions: hence homogeneous transformational matrix ${ }_{S}^{Z} \mathbf{T}^{i}$ is a unit matrix I. The homogeneous transformational matrix ${ }_{X}^{W} \mathbf{T}^{i}$ between workpiece coordinate system and $X$-axis coordinate system is a unit matrix $\mathbf{I}$. The total transformation matrix of geometric errors between initial coordinate and destination coordinate can be obtained by multiplication of homogeneous transformational matrix. The coordinate position of cutting tool in the workpiece coordinate system can be expressed as

$$
{ }_{T}^{W} \mathbf{T}^{i}={ }_{X}^{W_{X}} \mathbf{T}_{Y}^{i}{ }_{Y}^{X} \mathbf{T}^{i} \cdot{ }_{R}^{Y} \mathbf{T}^{i} \cdot{ }_{Z}^{R} \mathbf{T}^{i} \cdot{ }_{S}^{Z} \mathbf{T}^{i} \cdot{ }_{T}^{S_{T}} \mathbf{T} .
$$

In practice, moving components of machine tools are affected by geometric errors. Based on features of geometric error and homogeneous coordinate transformation matrixes, coordinate transformation of the component of CNC machine tool in the local coordinate systems can be expressed with the product of homogeneous coordinate transformation matrix. ${ }_{m}^{n} \mathbf{T}^{e}$ represents the error transformational matrix from $m$ coordinate system to $n$ coordinate system. According to the assumption of small angle approximation, the error 
transformational matrix can be obtained, as shown in the following:

$$
\begin{aligned}
{ }_{Y}^{X} \mathbf{T}^{e} & =\left[\begin{array}{cccc}
1 & -\varepsilon_{z}(x) & \varepsilon_{y}(x) & \delta_{x}(x) \\
\varepsilon_{z}(x) & 1 & -\varepsilon_{x}(x) & \delta_{y}(x) \\
-\varepsilon_{y}(x) & \varepsilon_{x}(x) & 1 & \delta_{z}(x) \\
0 & 0 & 0 & 1
\end{array}\right], \\
{ }_{R} \mathbf{T}^{e} & =\left[\begin{array}{cccc}
1 & -\varepsilon_{z}(y) & \varepsilon_{y}(y) & \delta_{x}(y)-y \cdot S_{x y} \\
\varepsilon_{z}(y) & 1 & -\varepsilon_{x}(y) & \delta_{y}(y) \\
-\varepsilon_{y}(y) & \varepsilon_{x}(y) & 1 & \delta_{z}(y) \\
0 & 0 & 0 & 1
\end{array}\right], \\
{ }_{Z}^{R} \mathbf{T}^{e} & =\left[\begin{array}{cccc}
1 & -\varepsilon_{z}(z) & \varepsilon_{y}(z) & \delta_{x}(z)-z \cdot S_{x z} \\
\varepsilon_{z}(z) & 1 & -\varepsilon_{x}(z) & \delta_{y}(z)-z \cdot S_{y z} \\
-\varepsilon_{y}(y) & \varepsilon_{x}(z) & 1 & \delta_{z}(z) \\
0 & 0 & 0 & 1
\end{array}\right] .
\end{aligned}
$$

Therefore, the coordinate position of cutting tool in the workpiece coordinate system under actual operation conditions can be expressed as

$$
\begin{aligned}
{ }_{T}^{W} \mathbf{T}^{e}= & { }_{X}{ }_{X} \mathbf{T}^{i} \cdot{ }_{X} \mathbf{T}^{e} \cdot{ }_{Y}^{X} \mathbf{T}^{i} \cdot{ }_{Y}^{X} \mathbf{T}^{e} \cdot{ }_{R}^{Y} \mathbf{T}^{i} \cdot{ }_{R}^{Y} \mathbf{T}^{e} \cdot{ }_{Z}^{R} \mathbf{T}^{i} \cdot{ }_{Z}^{R} \mathbf{T}^{e} \\
& \cdot{ }_{S}^{Z} \mathbf{T}^{i} \cdot{ }_{S}^{Z_{S}} \mathbf{T}^{e} \cdot{ }_{T}^{S^{S}} \mathbf{T}^{i} \cdot{ }_{T} \mathbf{T} .
\end{aligned}
$$

The cutting point will inevitably deviate from the ideal position under the influence of geometric errors and the output positioning error of three-axis machine tool can be expressed as

$$
\mathbf{E}_{T}\left(\mathbf{E}_{x}, \mathbf{E}_{y}, \mathbf{E}_{z}\right)=\left({ }_{T}^{W} \mathbf{T}^{e}-{ }_{T}{ }_{T} \mathbf{T}^{i}\right) \times\left[\begin{array}{llll}
0 & 0 & 0 & 1
\end{array}\right]^{T} .
$$

The components of error $\mathbf{E}_{T}\left(\mathbf{E}_{x}, \mathbf{E}_{y}, \mathbf{E}_{z}\right)$ can be obtained by substituting the homogeneous coordinate transformation matrixes into (5), in which the error's cubic and higher terms are neglected

$$
\begin{aligned}
\mathbf{E}_{x} & =\delta_{x}(z)+\delta_{x}(x)+\delta_{x}(y)-y\left[\varepsilon_{z}(x)+S_{x y}\right]+D_{2} \\
\cdot & {\left[-\varepsilon_{z}(x)-\varepsilon_{z}(y)-\varepsilon_{z}(z)\right]+z\left[\varepsilon_{y}(x)+\varepsilon_{y}(y)\right.} \\
& \left.-S_{x z}+\varepsilon_{z}(x) \cdot \varepsilon_{x}(y)+\varepsilon_{z}(x) \cdot S_{y z}+\varepsilon_{z}(y) \cdot S_{y z}\right] \\
& -\varepsilon_{z}(y) \cdot \delta_{y}(z)+\varepsilon_{y}(x)\left[\delta_{z}(y)+\delta_{z}(z)\right]+\varepsilon_{y}(y)
\end{aligned}
$$

$$
\begin{aligned}
& \cdot \delta_{z}(z)+D_{3}\left[\varepsilon_{y}(x)+\varepsilon_{y}(y)+\varepsilon_{y}(z)+\varepsilon_{x}(y)\right. \\
& \left.\cdot \varepsilon_{z}(x)+\varepsilon_{x}(z) \cdot \varepsilon_{z}(x)+\varepsilon_{x}(z) \cdot \varepsilon_{z}(y)\right]-\varepsilon_{z}(x) \\
& \cdot\left[\delta_{y}(y)+\delta_{y}(z)\right] \\
& \mathbf{E}_{y}=\delta_{y}(z)+\delta_{y}(x)+\delta_{y}(y)+D_{1}\left[\varepsilon_{z}(y)+\varepsilon_{z}(x)\right. \\
& \left.+\varepsilon_{z}(z)\right]+\delta_{z}(x) \cdot\left[\delta_{x}(y)+\delta_{x}(z)\right]-z\left[\varepsilon_{x}(x)\right. \\
& +\varepsilon_{x}(y)+S_{y z}-\varepsilon_{y}(y) \cdot \varepsilon_{z}(x)+\varepsilon_{z}(x) \cdot S_{x z} \\
& \left.+\varepsilon_{z}(y) \cdot S_{x z}\right]-y \cdot \varepsilon_{z}(x) \cdot S_{x y}-\varepsilon_{x}(y) \cdot \delta_{z}(z) \\
& +\delta_{x}(z) \cdot \varepsilon_{z}(y)-D_{3}\left[\varepsilon_{x}(x)+\varepsilon_{x}(y)+\varepsilon_{x}(z)\right. \\
& \left.-\varepsilon_{y}(y) \cdot \varepsilon_{z}(x)-\varepsilon_{y}(z) \cdot \varepsilon_{z}(x)-\varepsilon_{y}(z) \cdot \varepsilon_{z}(y)\right] \\
& -\varepsilon_{x}(x)\left[\delta_{z}(y)+\delta_{z}(z)\right], \\
& \mathbf{E}_{z}=\delta_{z}(z)+\delta_{z}(x)+\delta_{z}(y)+y\left[\varepsilon_{y}(x) \cdot S_{x y}+\varepsilon_{x}(x)\right] \\
& +\varepsilon_{x}(x)\left[\delta_{y}(y)+\delta_{y}(z)\right]-\varepsilon_{y}(x)\left[\delta_{x}(y)+\delta_{x}(z)\right] \\
& -z\left[S_{y z} \cdot \varepsilon_{x}(x)+\varepsilon_{x}(y) \cdot \varepsilon_{x}(x)-\varepsilon_{y}(x) \cdot S_{x z}\right. \\
& \left.+\varepsilon_{y}(x) \cdot \varepsilon_{y}(y)-\varepsilon_{y}(y) \cdot S_{x z}+\varepsilon_{x}(y) \cdot S_{y z}\right] \\
& +\varepsilon_{x}(y) \cdot \delta_{y}(z)-D_{3}\left[\varepsilon_{x}(y) \cdot \varepsilon_{x}(x)+\varepsilon_{x}(z)\right. \\
& \cdot \varepsilon_{x}(x)+\varepsilon_{y}(y) \cdot \varepsilon_{y}(x)+\varepsilon_{y}(z) \cdot \varepsilon_{y}(x)+\varepsilon_{x}(y) \\
& \left.\cdot \varepsilon_{x}(z)+\varepsilon_{y}(y) \cdot \varepsilon_{y}(z)\right]-\delta_{x}(z) \cdot \varepsilon_{y}(y) \\
& +D_{1}\left[-\varepsilon_{y}(x)-\varepsilon_{y}(y)-\varepsilon_{y}(z)\right]+D_{2}\left[\varepsilon_{x}(x)\right. \\
& \left.+\varepsilon_{x}(y)+\varepsilon_{x}(z)\right] \text {. }
\end{aligned}
$$

The total volumetric error vector $\mathbf{E}_{T}$ is defined as follows:

$$
\mathbf{E}_{T}=\sqrt{\left(\mathbf{E}_{x}\right)^{2}+\left(\mathbf{E}_{y}\right)^{2}+\left(\mathbf{E}_{z}\right)^{2}} .
$$

The volumetric error model was built on the basis of multibody system theory, which includes 21 geometric errors. The model includes the deviation of actual location from ideal location for cutting point in the workpiece coordinate, which can be used for global sensitivity analyzing and to calculate the compensation values.

2.3. Error Measurement and Identification of Three-Axis Machine Tools. Many measurement devices are available for identifying the geometric errors according to the testing standard [34, 35] and corresponding methods have been adopted in measurement and identification of 21 geometric errors in three-axis machine tools. In this study, the twelveline method [36] is applied to identify the geometric error elements for each axis based on Renishaw XL-80 laser interferometer measuring system, as shown in Figure 2. 


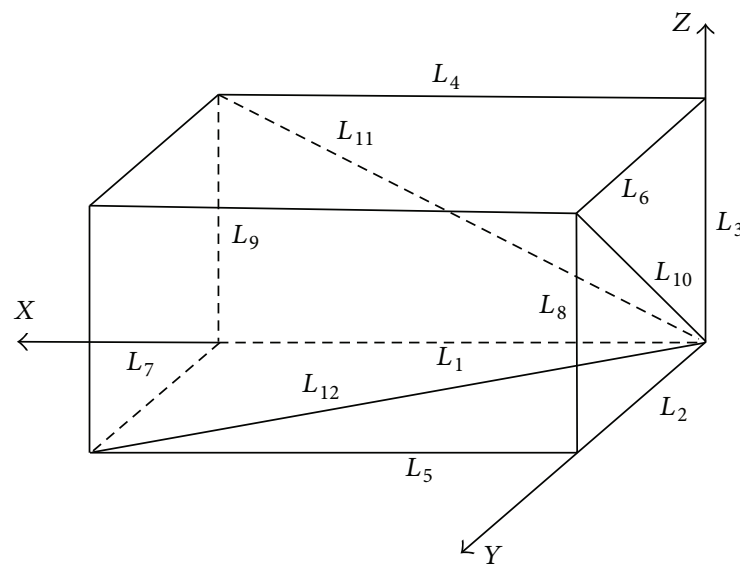

(a)

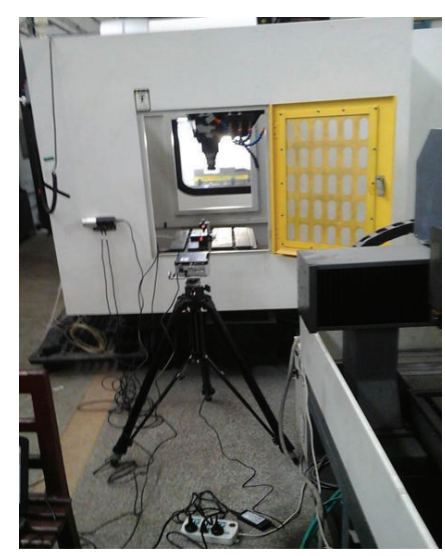

(b)

Figure 2: Twelve measurement lines and experiment setup; (a) twelve-line measure diagram for linear axes; and (b) experiment setup with laser interferometer.

The measurement of twelve lines can be implemented by single-axis motion and double-axis simultaneous motion, and the scale errors along the twelve lines were measured at twelve mm intervals. According to ISO 230-1 [34], three consecutive measurements were conducted to weaken the influence of stochastic characteristics of geometric error elements. The 21 geometric error elements were identified by solving linear equations, and the measurement results showed that the measurement accuracy obtained a satisfactory consistency.

\section{Global Sensitivity Analysis of Volumetric Error}

3.1. Global Sensitivity Analysis Modeling. Since the geometric errors of machine tools obey a normal distribution [21, 37] and there is an inherent coupling in the geometric error elements, geometric error elements often fluctuate in a certain range. The geometric error elements are sorted according to the contribution of the different factors based on globally quantitative sensitivity analysis. In this paper, the global sensitivity analysis of geometric errors is carried out for identifying and compensating the key geometric errors.

The EFAST approach is to obtain the expectation and variance of a model output. The basis of this calculation is a transformation that converts a multidimensional integral over all the uncertain model inputs to a one-dimensional integral [38]. The global sensitivity analysis is proposed based on variance-based method. The distinct integer frequencies are assigned to geometric error elements by using a periodic sampling function. For a specific geometric error element, the variance of the model outputs corresponding to eigenfrequencies can reflect the effect of input parameters on the results of output.

The error model is established by MBS theory and HTM in the above section, and the volumetric error model can be assumed as $Y=f\left(x_{1}, x_{2}, \ldots, x_{n}\right)$, where $n$ is the number of geometric errors. Each parameter has its own corresponding variable range and probability distribution, and all the geometric error elements make up a multidimensional parameter space. The main steps of EFAST method are as follows:

(1) Firstly, transform the $Y=f\left(x_{1}, x_{2}, \ldots, x_{n}\right)$ into $y=$ $f(s)$ with defined Saltelli search function $G_{i}[32]$ :

$$
x_{i}=G_{i}\left[\sin \left(w_{i} s\right)\right], \quad i=1,2, \ldots, n,
$$

where $w_{i}$ is the preset frequency for $x_{i}, s$ is the scalar, and the range of $s$ is $-\infty<s<+\infty$.

The expression form for $y=f(s)$ by Fourier transform can be obtained as

$$
y=f(s)=\sum_{p=-\infty}^{+\infty}\left|A_{p} \cos (p s)+B_{p} \sin (p s)\right|,
$$

where $p$ is Fourier transform parameters, $p \in Z=$ $\{-\infty, \ldots,-1,0,1, \ldots,+\infty\}$, and Fourier coefficient can be expressed as follows:

$$
\begin{aligned}
& A_{p}=\frac{1}{2 \pi} \int_{-\pi}^{\pi} f(s) \cdot \cos (p s) d s \\
& B_{p}=\frac{1}{2 \pi} \int_{-\pi}^{\pi} f(s) \cdot \sin (p s) d s .
\end{aligned}
$$

The frequency curves of Fourier series can be expressed as

$$
\Lambda_{p}=A_{p}^{2}+B_{p}^{2}
$$

where $A_{-p}=A_{p}, B_{-p}=B_{p}$, and $\Lambda_{-p}=\Lambda_{p}$.

(2) Secondly, frequency curves $\Lambda_{p}$ are obtained; $V_{i}$ is defined as the variance of the output results while input parameters (geometric error elements) vary. Variance is expressed by the following:

$$
V_{i}=\sum_{p \in Z^{0}} \Lambda_{p} w_{i}=2 \sum_{j=1}^{+\infty} \Lambda_{j} w_{i}
$$

where $Z^{0}=Z-\{0\}$, and $Z^{0}$ is a nonzero integer number. 
The total variance of volumetric error vector is calculated by the following:

$$
V=\sum_{p \in Z^{0}} \Lambda_{p}=2 \sum_{j=1}^{+\infty} \Lambda_{j}
$$

Equal interval sampling for $s$ is conducted from $-\pi$ to $+\pi$ to obtain model input parameters, and multiple runs are made to get output results. Solve (10) based on Monte Carlo integration method to obtain approximate values as follows:

$$
\begin{aligned}
& A_{P}=\frac{1}{N_{s}} \sum_{k=1}^{N_{s}} f\left(s_{k}\right) \cdot \cos \left(j s_{k}\right), \\
& B_{P}=\frac{1}{N_{s}} \sum_{k=1}^{N_{s}} f\left(s_{k}\right) \cdot \sin \left(j s_{k}\right),
\end{aligned}
$$

where $p \in Z=\left\{-\left(N_{s}-1\right) / 2, \ldots,-1,0,1, \ldots,\left(N_{s}-1\right) / 2\right\}$ and $N_{s}$ is the number of samples.

(3) Finally, the total variance is divided into the sum of variances and the sensitivity coefficients are determined. The total variance can be decomposed as follows:

$$
V=\sum_{i} V_{i}+\sum_{i \neq j} V_{i j}+\sum_{i \neq j \neq m} V_{i j m}+\cdots+V_{12 \cdots k} \text {, }
$$

where $V_{i}$ represents the first-order effect for each factor $x_{i}$ and $V_{i j}, \ldots, V_{12 \cdots k}$ represent the variances of coupling effect of geometric errors.

Sensitivity coefficient is defined with the normalization processing as follows:

$$
S_{i}=\frac{V_{i}}{V}
$$

The above sensitivity coefficients represent the direct contribution to total variance of volumetric error caused by each input parameter. Similarly, second-order and thirdorder sensitivity coefficient of error element $x_{i}$ are shown as follows:

$$
\begin{gathered}
S_{i j}=\frac{V_{i j}}{V}, \\
S_{i j m}=\frac{V_{i j m}}{V} .
\end{gathered}
$$

In a multiparameters model, the global sensitivity coefficient of error elements $x_{i}$ is the sum of sensitivity coefficients of all order, that is,

$$
S_{T j}=S_{i}+S_{i j}+S_{i j m}+\cdots+S_{12 \cdots k}
$$

The first-order sensitivity and global sensitivity coefficient of input parameters can be obtained simultaneously by the EFAST method; they represent the influence of single parameter on machine precision and the coupling effect on machine precision, respectively.
3.2. Global Sensitivity Analysis of Geometric Errors. On the basis of predefined measurement trajectory, the geometric error measurements are carried out as described in Section 2.3, and the 21 geometric error elements can be obtained by corresponding algorithms. Table 2 shows the probabilistic characteristics of input parameters (geometric errors) of a three-axis machine tool.

The values of geometric errors are related to NC instructions. Let $\mathrm{NC}$ instructions be random varying with uniform distribution within the stroke of motion axes; and thus the influence of geometric errors in the entire workspace can be considered sufficiently without loss of generality.

The GSA model is established based on geometric error model and the GSA method in Section 3.1. The calculation results are effective when the sampling number is more than 65 times the number of geometric error elements; therefore, 1400 samples for each parameter are introduced into GSA model of geometric errors.

The first-order sensitivity coefficient and global sensitivity coefficient are calculated and the analysis results are shown in Figures 3 and 4. Figure 3 shows the first-order sensitivity analysis result for $\mathbf{E}_{x}, \mathbf{E}_{y}, \mathbf{E}_{z}$, and $\mathbf{E}_{T}$; and Figure 4 shows the global sensitivity analysis result for $\mathbf{E}_{x}, \mathbf{E}_{y}, \mathbf{E}_{z}$, and $\mathbf{E}_{T}$.

As shown in Figure 3, the first-order sensitivities of the first six geometric errors $\left(\delta_{x}(x), \delta_{x}(z), \delta_{x}(y), \varepsilon_{x}(x), \varepsilon_{y}(x)\right.$, and $S_{x z}$ ) are larger in the $X$ direction; and the sensitivity coefficients are $0.3,0.23,0.14,0.05,0.04$, and 0.03 , respectively, which are the key factors affecting the $\mathbf{E}_{x}$. The global sensitivities of the first six geometric errors $\left(\delta_{x}(x), \delta_{z}(x)\right.$, $\varepsilon_{z}(x), \delta_{x}(z), \delta_{x}(y)$, and $\left.S_{x y}\right)$ in Figure 4 are larger in the $X$ direction, and the sensitivity coefficients are $0.17,0.16,0.09$, $0.08,0.06$, and 0.04 , respectively; this means that $\delta_{x}(x), \delta_{z}(x)$, $\varepsilon_{z}(x), \delta_{x}(z), \delta_{x}(y)$, and $S_{x y}$ have intense coupling effects with other geometric errors on $\mathbf{E}_{x}$. In the $Y$ direction, the firstorder sensitivities of the first six geometric errors $\left(\delta_{y}(y)\right.$, $\delta_{x}(z), \delta_{y}(z), \delta_{z}(x), \varepsilon_{x}(y)$, and $\left.\varepsilon_{y}(x)\right)$ in Figure 3 are larger, and the sensitivity coefficients are $0.32,0.28,0.18,0.07,0.03$, and 0.02 , respectively, which are the key factors affecting the $\mathbf{E}_{y}$. The global sensitivities of the first six geometric errors $\left(\delta_{y}(y), \varepsilon_{x}(z), \delta_{x}(z), \delta_{y}(z), \varepsilon_{x}(y)\right.$, and $\left.\delta_{x}(x)\right)$ in Figure 4 are larger in the $Y$ direction, and the sensitivity coefficients are $0.19,0.17,0.12,0.11,0.04$, and 0.03 , respectively, which have intense coupling effects with other geometric errors on $\mathbf{E}_{y}$. In the $Z$ direction, the first-order sensitivities of the first six geometric errors $\left(\delta_{z}(z), \delta_{z}(x), \delta_{z}(y), \varepsilon_{x}(x), \delta_{y}(x)\right.$, and $\left.\delta_{x}(z)\right)$ in Figure 3 are $0.39,0.28,0.05,0.04,0.03$, and 0.02, respectively, which are the key factors affecting the $\mathbf{E}_{z}$. The global sensitivities of the first six geometric errors $\left(\delta_{z}(z)\right.$, $\delta_{z}(x), \varepsilon_{z}(y), S_{x y}, \varepsilon_{z}(z)$, and $\left.\varepsilon_{x}(z)\right)$ in Figure 4 are larger in the $Z$ direction; and the sensitivity coefficients are $0.19,0.09$, $0.06,0.05,0.05$, and 0.04 , respectively, which indicates that the above six geometric errors have intense coupling effects with other geometric errors on $\mathbf{E}_{z}$.

The first-order sensitivities of the first six geometric errors $\left(\delta_{z}(z), \delta_{x}(x), \delta_{x}(z), \delta_{y}(y), \delta_{z}(x)\right.$, and $\left.\delta_{y}(z)\right)$ in Figure 3 are larger in the workspace for total volumetric error vector $\mathbf{E}_{T}$, and the sensitivity coefficients are $0.24,0.23,0.20,0.13,0.07$, and 0.03 , respectively, which are the key factors affecting the $\mathbf{E}_{T}$. The global sensitivity coefficients of the first six geometric 
TABLE 2: The probabilistic characteristics of geometric errors.

\begin{tabular}{|c|c|c|c|c|}
\hline Error term & Unit & Probability distribution & Mean value & Stand deviation \\
\hline$\varepsilon_{x}(x)$ & $10^{-4} \cdot \mathrm{rad}$ & Normal & 0.01 & $6.98 e-03$ \\
\hline$\varepsilon_{y}(x)$ & $10^{-4} \cdot \mathrm{rad}$ & Normal & 0.32 & $4.29 e-03$ \\
\hline$\varepsilon_{z}(x)$ & $10^{-4} \cdot \mathrm{rad}$ & Normal & -0.01 & $5.94 e-03$ \\
\hline$\delta_{x}(x)$ & $\mu \mathrm{m}$ & Normal & 9.90 & 0.3531 \\
\hline$\delta_{y}(x)$ & $\mu \mathrm{m}$ & Normal & 0.30 & 0.0286 \\
\hline$\delta_{z}(x)$ & $\mu \mathrm{m}$ & Normal & 1.20 & 0.0874 \\
\hline$\varepsilon_{x}(y)$ & $10^{-4} \cdot \mathrm{rad}$ & Normal & -0.08 & $2.49 e-03$ \\
\hline$\varepsilon_{y}(y)$ & $10^{-4} \cdot \mathrm{rad}$ & Normal & -0.03 & $3.95 e-03$ \\
\hline$\varepsilon_{z}(y)$ & $10^{-4} \cdot \mathrm{rad}$ & Normal & 0.54 & $6.54 e-03$ \\
\hline$\delta_{x}(y)$ & $\mu \mathrm{m}$ & Normal & 1.50 & 0.0899 \\
\hline$\delta_{y}(y)$ & $\mu \mathrm{m}$ & Normal & 6.20 & 0.6354 \\
\hline$\delta_{z}(y)$ & $\mu \mathrm{m}$ & Normal & 0.50 & 0.0411 \\
\hline$\varepsilon_{x}(z)$ & $10^{-4} \cdot \mathrm{rad}$ & Normal & -0.01 & $5.89 e-03$ \\
\hline$\varepsilon_{y}(z)$ & $10^{-4} \cdot \mathrm{rad}$ & Normal & 0.24 & $6.77 e-03$ \\
\hline$\varepsilon_{z}(z)$ & $10^{-4} \cdot \mathrm{rad}$ & Normal & 0.21 & $5.18 e-03$ \\
\hline$\delta_{x}(z)$ & $\mu \mathrm{m}$ & Normal & 0.40 & 0.1541 \\
\hline$\delta_{y}(z)$ & $\mu \mathrm{m}$ & Normal & 0.30 & 0.2492 \\
\hline$\delta_{z}(z)$ & $\mu \mathrm{m}$ & Normal & 8.70 & 0.4160 \\
\hline$S_{x y}$ & $10^{-4} \cdot \mathrm{rad}$ & Normal & -1.18 & $1.93 e-02$ \\
\hline$S_{x z}$ & $10^{-4} \cdot \mathrm{rad}$ & Normal & -3.29 & $6.64 e-02$ \\
\hline$S_{y z}$ & $10^{-4} \cdot \mathrm{rad}$ & Normal & 0.27 & $6.19 e-02$ \\
\hline
\end{tabular}

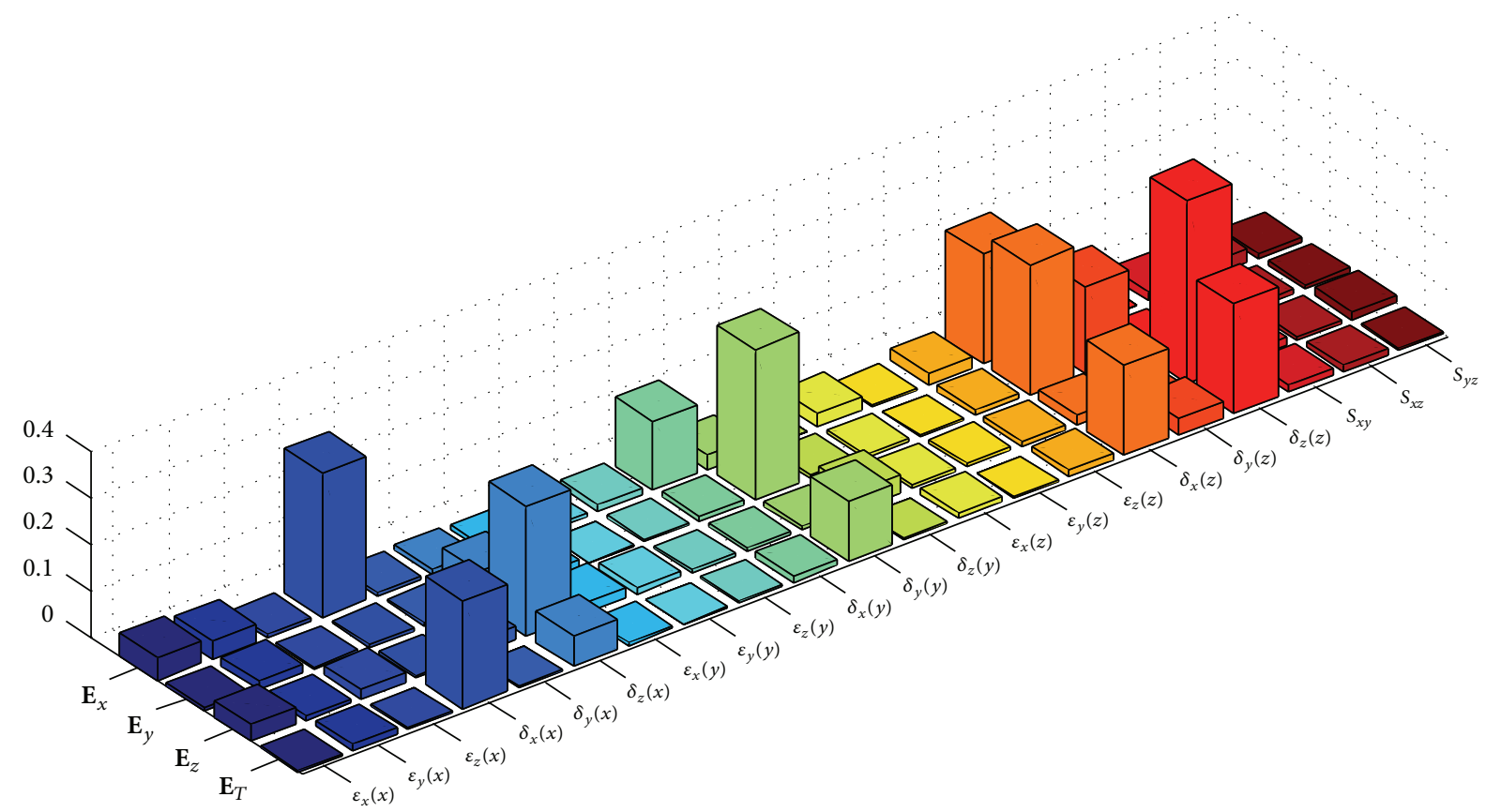

FIGURE 3: First-order sensitivity of geometric errors in the workspace. 


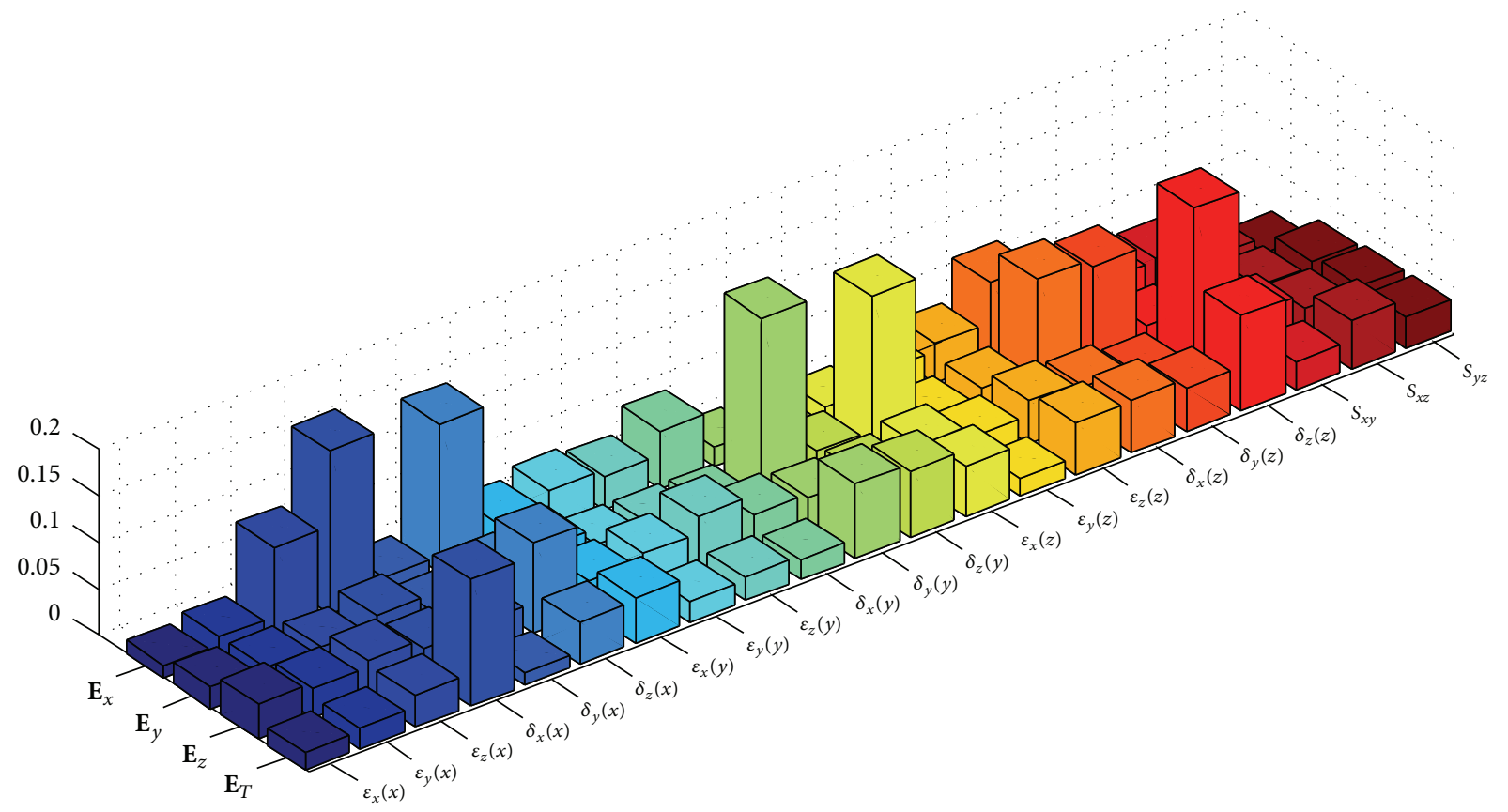

FIGURE 4: Global sensitivity of geometric errors in the workspace.

errors $\left(\delta_{x}(x), \delta_{z}(z), \delta_{y}(y), \delta_{z}(y), \delta_{x}(z)\right.$, and $\left.\varepsilon_{z}(z)\right)$ in Figure 4 are larger in the entire workspace for total volumetric error vector $\mathbf{E}_{T}$, and the sensitivity coefficients are $0.14,0.10,0.08$, $0.07,0.06$, and 0.06 , respectively, which have intense coupling effects with other geometric errors on $\mathbf{E}_{T}$.

The results of GSA show that scale errors and straightness errors are the major factors of geometric error elements, and angular errors and squareness errors have smaller sensitivity coefficients. Besides, the sensitivity coefficients of scale errors are higher than those of the corresponding components in total volumetric error vector. The geometric errors with larger first-order sensitivity coefficients and global sensitivity coefficients have obvious effect on the precision of machines compared to other geometric error elements. These errors should be strictly controlled through rational tolerance allocation in the design of machine tool or error compensation. Meanwhile, the sensitivity coefficients can be used for improving the precision of machine tools by controlling the key geometric error elements of correlative motion axes in the machining and error compensating processes.

\section{Geometric Error Compensation Based on GSA}

4.1. Geometric Error Compensation Strategy. Error compensation is extremely important to validate geometric error model and improve machine tool precision. The actual location of motion axes can be compensated by adding compensation values in reverse. Real-time compensation was obtained by external mechanical origin offset and adaptive fuzzy control method in previous studies [39, 40]. However, the random nature and coupled effect of geometric errors were not considered comprehensively. Therefore, in this paper geometric error compensation was implemented based on the results of global quantitative sensitivity analysis.

Geometric errors obey normal distribution; $\mu$ and $\sigma$ represent the mean and standard deviation, respectively. Distribution center of geometric errors and tolerance zone are overlapped, and geometric errors vary in the range of $[\mu-3 \sigma, \mu+3 \sigma]$ with $99.73 \%$ of probability. It means that the confidence level is higher. The relationship between variance $\left(\sigma_{i}^{2}\right)$ of individual geometric error and tolerance $(T)$ of total volumetric error can be expressed as follows:

$$
S_{i}=\frac{6 \sigma_{i}^{2}}{T}=\frac{V_{i}}{V} .
$$

The relationships between tolerance, standard deviation, and sensitivity coefficient are established by the above methods. First-order sensitivity is the main sensitivity of geometric errors, and sensitivity coefficient represents the direct contribution to total variance of volumetric error. Hence, first-order sensitivity coefficient of volumetric error is selected as input parameters in (19). The volumetric error of high-precision three-axis machine tool is less than $25 \mu \mathrm{m}$ according to the design accuracy requirement. Based on first-order sensitivity and the design accuracy of machine tool, the stand deviation of compensation values of individual geometric error element can be obtained.

The compensation values can be calculated by using the geometric error model, identification values, and NC 
TABLE 3: The stand deviation of compensation values of individual geometric error.

\begin{tabular}{lcc}
\hline Error term & Unit & Stand deviation \\
\hline$\varepsilon_{x}(x)$ & $10^{-4} \cdot \mathrm{rad}$ & $5.0017 e-4$ \\
$\varepsilon_{y}(x)$ & $10^{-4} \cdot \mathrm{rad}$ & $1.7590 e-3$ \\
$\varepsilon_{z}(x)$ & $10^{-4} \cdot \mathrm{rad}$ & $4.2241 e-4$ \\
$\delta_{x}(x)$ & $\mu \mathrm{m}$ & 0.97 \\
$\delta_{y}(x)$ & $\mu \mathrm{m}$ & 0.01 \\
$\delta_{z}(x)$ & $\mu \mathrm{m}$ & 0.28 \\
$\varepsilon_{x}(y)$ & $10^{-4} \cdot \mathrm{rad}$ & $6.7670 e-4$ \\
$\varepsilon_{y}(y)$ & $10^{-4} \cdot \mathrm{rad}$ & $1.1601 e-4$ \\
$\varepsilon_{z}(y)$ & $10^{-4} \cdot \mathrm{rad}$ & $7.2714 e-4$ \\
$\delta_{x}(y)$ & $\mu \mathrm{m}$ & 0.06 \\
$\delta_{y}(y)$ & $\mu \mathrm{m}$ & 0.54 \\
$\delta_{z}(y)$ & $\mu \mathrm{m}$ & 0.01 \\
$\varepsilon_{x}(z)$ & $10^{-4} \cdot \mathrm{rad}$ & $1.8178 e-3$ \\
$\varepsilon_{y}(z)$ & $10^{-4} \cdot \mathrm{rad}$ & $1.7548 e-4$ \\
$\varepsilon_{z}(z)$ & $10^{-4} \cdot \mathrm{rad}$ & $1.9334 e-3$ \\
$\delta_{x}(z)$ & $\mu \mathrm{m}$ & 0.81 \\
$\delta_{y}(z)$ & $\mu \mathrm{m}$ & 0.14 \\
$\delta_{z}(z)$ & $\mu \mathrm{m}$ & 0.98 \\
$S_{x y}$ & $10^{-4} \cdot \mathrm{rad}$ & $2.1226 e-3$ \\
$S_{x z}$ & $10^{-4} \cdot \mathrm{rad}$ & $1.6182 e-3$ \\
$S_{y z}$ & $10^{-4} \cdot \mathrm{rad}$ & $4.8336 e-4$ \\
\hline & &
\end{tabular}

instructions. The mean of compensation values equals the identification value of repeated measurement results; and the stand deviation of compensation values depends on the analysis results of GSA, as summarized in Table 3 .

The stochastic characteristics and coupling feature of geometric errors can be effectively controlled by way of selecting compensation value in the rational region.

4.2. Error Compensation and Validation. Geometric error compensation is conducted based on the position control in servo control system [41]; and the interpolating instructions are modified in front-end of bus interface. The error compensation is accomplished by the feedback outage compensation method, as shown in Figure 5.

To verify the effectiveness of geometric error compensation method in this paper, a high-precision three-axis machine tool was built. The main technical specifications of the machine tool are shown in Table 4.

The high-precision three-axis machine tool consists of servo motors, amplifiers, and mechanical part, which is controlled by an open CNC system based on dSPACE. The open CNC system consists of host computer and slave computer [42]. Human-machine interaction code generation and data preservation can be realized using host computer based on special software of dSPACE, and real-time control and signal acquisition can be realized by the slave computer. The control signals are generated by the motion controller and then transmitted to amplifier. The position feedback signals are produced by the linear scale; meanwhile, the position signals, velocity signals, and torque signals are transmitted via data bus to the host computer. The high-precision three-axis machine tool with open CNC system is shown in Figure 6.

Measurements are performed again and the geometric errors are identified with the geometric error model after compensation. Figure 7 shows the comparison results before and after the error compensation.

Error components $\mathbf{E}_{x}, \mathbf{E}_{y}$, and $\mathbf{E}_{z}$ are measured and identified after error compensation. The error components are much smaller compared to without compensation, and $\mathbf{E}_{x}, \mathbf{E}_{y}$, and $\mathbf{E}_{z}$ with compensation are $-6.4-5.5 \mu \mathrm{m},-4.2-$ $4.6 \mu \mathrm{m}$, and $-2.1-1.6 \mu \mathrm{m}$, respectively. The geometric error components $\mathbf{E}_{x}, \mathbf{E}_{y}$, and $\mathbf{E}_{z}$ without compensation are -13.6$14.8 \mu \mathrm{m},-12.8-11.2 \mu \mathrm{m}$, and $-6.7-0 \mu \mathrm{m}$, respectively. The average compensation rates along the $X, Y$, and $Z$ directions are $59.8 \%, 65.5 \%$, and $73.5 \%$, respectively.

The results before and after geometric error compensation show that the geometric errors of three-axis machine tool can be compensated effectively by using open CNC system, and the compensation method based on GSA is effective in improving machining precision.

\section{Conclusion}

There exists coupling effect between geometric errors and it should be considered in the process of error compensation. Local qualitative sensitivity analysis has been used to identify the key geometric errors in previous research. The coupling performance between errors and the effect of key geometric errors elements with respect to volumetric error vector are often ignored or cannot be quantized. Meanwhile, these sensitivity analysis results were not applied to error compensation of machine tools. Therefore, this paper presented a novel global quantitative sensitivity analysis and compensation method for improving precision of CNC machine tools. Some conclusions from this research can be drawn as follows:

(1) The critical geometric error elements are identified by using the first-order sensitivity analysis, and the geometric error elements with large coupling with others are quantitatively analyzed by using the global sensitivity analysis. The effect of each error element and the coupling relationships can be quantified by this method. Hence, the method can overcome the drawbacks of qualitative local sensitivity analysis method.

(2) Based on the results of global sensitivity analysis, the compensate method is proposed and the stochastic characteristics of the geometric errors of machine tools are compensated by using established quantitative relationship between stand variances and sensitivity coefficients. This method effectively breakouts the limitations of the analysis and compensation at certain locations. 
TABLE 4: Main specifications of the machine tool.

\begin{tabular}{lccc}
\hline$X / Y / Z$ stroke $(\mathrm{mm} \times \mathrm{mm})$ & Screw lead $/ \mathrm{mm}$ & Position accuracy $(X, Y$, and $Z) / \mathrm{mm}$ & Repeatability $(X, Y$, and $Z) / \mathrm{mm}$ \\
\hline $400 \times 400 \times 350$ & 16 & $0.005 / 0.005 / 0.005$ & $0.003 / 0.003 / 0.003$ \\
\hline
\end{tabular}

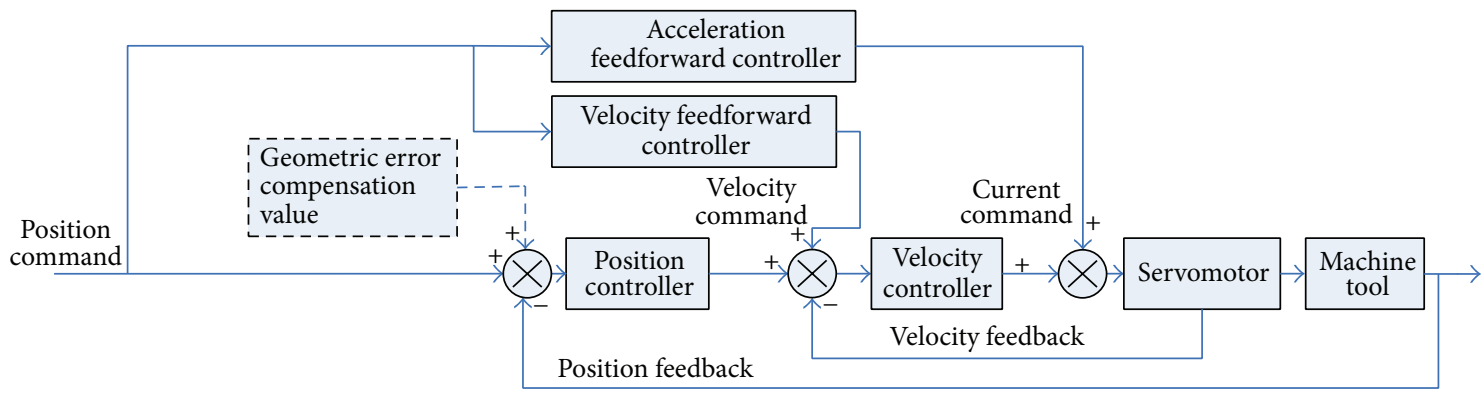

FIGURE 5: The principle of geometric error compensation.

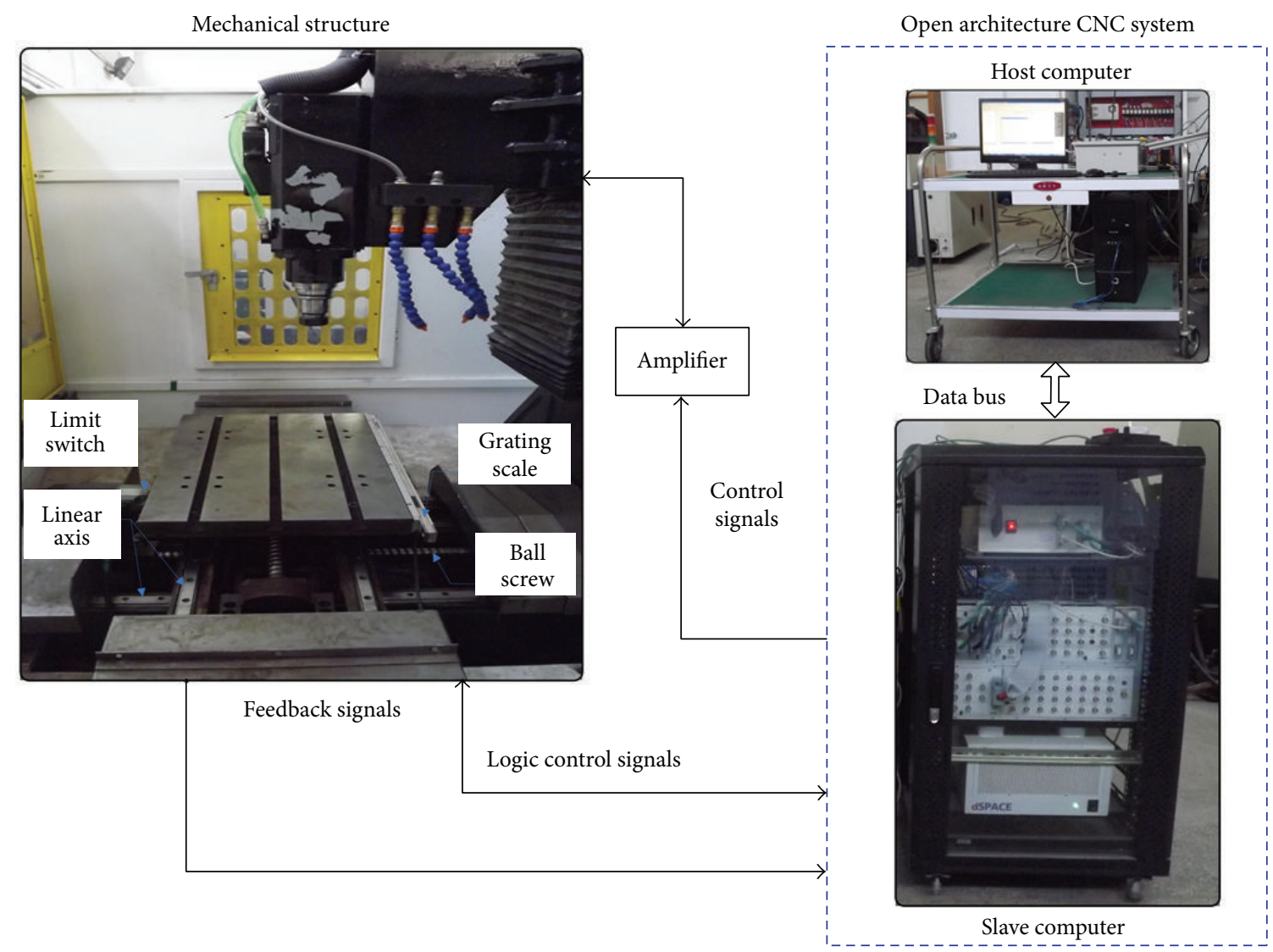

FIgURE 6: High-precision three-axis machine tool with open CNC system.

(3) The novel geometric error compensation method is verified on a three-axis machine tool with open CNC system. The results show that the precision of machine tool with compensation is improved significantly; and the average compensation rates along the $X, Y$, and $Z$ directions are $59.8 \%, 65.5 \%$, and $73.5 \%$, respectively, which is more adaptable to a practical operating mode.
The experiment results indicate that this approach is feasible to improve the precision of three-axis machine tool. Furthermore, the proposed analysis and compensate method can be extended to the accuracy allocation after conceptual design of multiaxis machine tools.

\section{Competing Interests}

The authors declare that they have no competing interests. 


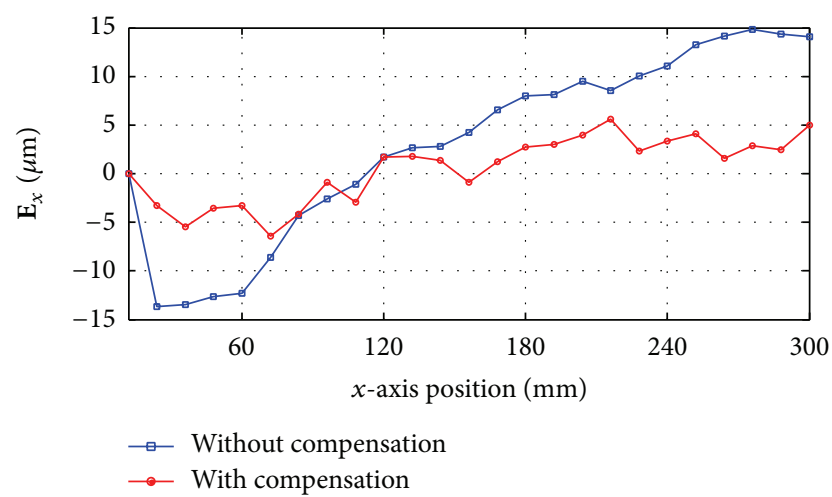

(a) Comparison of $\mathbf{E}_{x}$ for with and without compensation

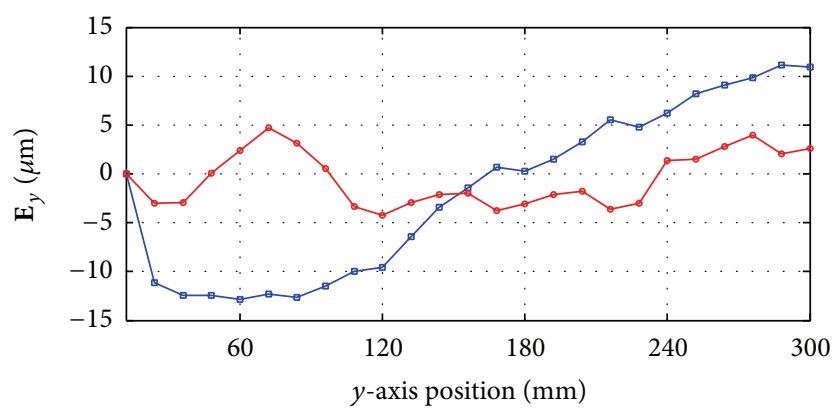

$\rightarrow$ Without compensation

$\because$ With compensation

(b) Comparison of $\mathbf{E}_{y}$ for with and without compensation

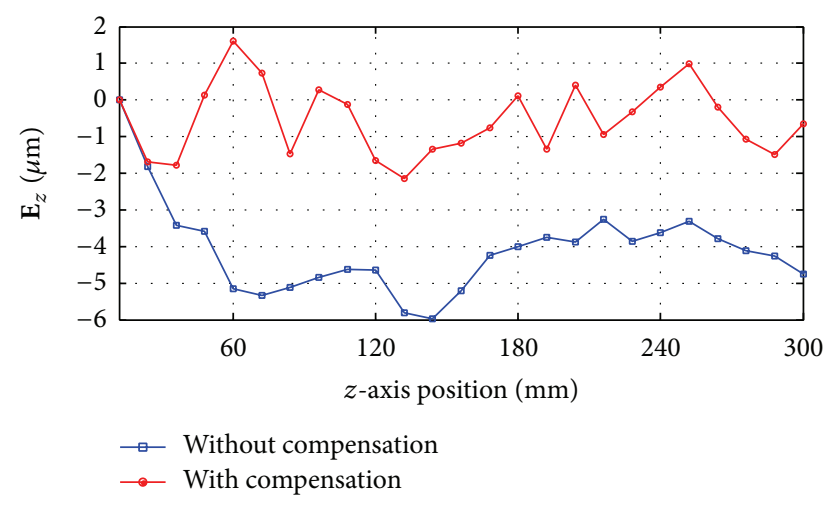

(c) Comparison of $\mathbf{E}_{z}$ for with and without compensation

FIGURE 7: Geometric error comparison results of the three-axis machine tool.

\section{Acknowledgments}

This study was supported by the Chinese National Science and Technology Key Special Projects (Grant no. 2014ZX04001051).

\section{References}

[1] R. Ramesh, M. A. Mannan, and A. N. Poo, "Error compensation in machine tools-a review. Part I. Geometric, cutting-force induced and fixture-dependent errors," International Journal of Machine Tools and Manufacture, vol. 40, no. 9, pp. 1235-1256, 2000 .
[2] X. B. Chen, A. Geddam, and Z. U. Yuan, "Accuracy improvement of three-axis CNC machining centers by quasi-static error compensation," Journal of Manufacturing Systems, vol. 16, no. 5, pp. 323-336, 1997.

[3] J. Ni, "CNC machine accuracy enhancement through realtime error compensation," Journal of Manufacturing Science and Engineering, vol. 119, no. 4, pp. 717-725, 1997.

[4] A. W. Khan and C. Wuyi, "Systematic geometric error modeling for workspace volumetric calibration of a 5-axis turbine blade grinding machine," Chinese Journal of Aeronautics, vol. 23, no. 5, pp. 604-615, 2010.

[5] G.-X. Wen, C. L. Chen, Y.-J. Liu, and Z. Liu, "Neural-networkbased adaptive leader-following consensus control for secondorder non-linear multi-agent systems," IET Control Theory and Applications, vol. 9, no. 13, pp. 1927-1934, 2015.

[6] K. F. Eman, B. T. Wu, and M. F. DeVries, "A generalized geometric error model for multi-axis machines," CIRP AnnalsManufacturing Technology, vol. 36, no. 1, pp. 253-256, 1987.

[7] R. Schultschik, "The components of the volumetric accuracy," Annals of the CIRP, vol. 25, no. 1, pp. 223-228, 1977.

[8] J. S. Chen, J. Yuan, and J. Ni, "Thermal error modelling for realtime error compensation," International Journal of Advanced Manufacturing Technology, vol. 12, no. 4, pp. 266-275, 1996.

[9] V. Kiridena and P. M. Ferreira, "Mapping the effects of positioning errors on the volumetric accuracy of five-axis CNC machine tools," International Journal of Machine Tools and Manufacture, vol. 33, no. 3, pp. 417-437, 1993.

[10] S. Yang, J. Yuan, and J. Ni, "Accuracy enhancement of a horizontal machining center by real-time error compensation," Journal of Manufacturing Systems, vol. 15, no. 2, pp. 113-124, 1996.

[11] Y. Lin and Y. Shen, "Modelling of five-axis machine tool metrology models using the matrix summation approach," The International Journal of Advanced Manufacturing Technology, vol. 21, no. 4, pp. 243-248, 2003.

[12] B. Sencer, Y. Altintas, and E. Croft, "Modeling and control of contouring errors for five-axis machine tools-part I: modeling," Journal of Manufacturing Science and Engineering, vol. 131, no. 3, Article ID 031006, pp. 1-8, 2009.

[13] Y. Liu, Y. Gao, S. Tong, and Y. Li, "Fuzzy approximation-based adaptive backstepping optimal control for a class of nonlinear discrete-time systems with dead-zone," IEEE Transactions on Fuzzy Systems, vol. 24, no. 1, pp. 16-28, 2016.

[14] J. Yang, J. R. R. Mayer, and Y. Altintas, "A position independent geometric errors identification and correction method for fiveaxis serial machines based on screw theory," International Journal of Machine Tools and Manufacture, vol. 95, pp. 52-66, 2015.

[15] G. Fu, J. Fu, Y. Xu, and Z. Chen, "Product of exponential model for geometric error integration of multi-axis machine tools," The International Journal of Advanced Manufacturing Technology, vol. 71, no. 9-12, pp. 1653-1667, 2014.

[16] Y. J. Liu, S. Tong, D. J. Li, and Y. Gao, "Fuzzy adaptive control with state observer for a class of nonlinear discrete-time systems with input constraint," IEEE Transactions on Fuzzy Systems, 2015.

[17] R. Houston and Y. Liu, Multi-Body System Dynamics, Tianjin University Press, Tianjin, China, 1991.

[18] A. C. Okafor and Y. M. Ertekin, "Derivation of machine tool error models and error compensation procedure for three axes vertical machining center using rigid body kinematics," 
International Journal of Machine Tools and Manufacture, vol. 40, no. 8, pp. 1199-1213, 2000.

[19] A. Saltelli, S. Tarantola, F. Campolongo, and M. Ratto, Sensitivity Analysis in Practice: A Guide to Assessing Scientific Models, John Wiley \& Sons, Chichester, UK, 2004.

[20] J. Nossent, P. Elsen, and W. Bauwens, "Sobol' sensitivity analysis of a complex environmental model," Environmental Modelling and Software, vol. 26, no. 12, pp. 1515-1525, 2011.

[21] Q. Cheng, C. Wu, P. Gu, W. Chang, and D. Xuan, "An analysis methodology for stochastic characteristic of volumetric error in multiaxis CNC machine tool," Mathematical Problems in Engineering, vol. 2013, Article ID 863283, 12 pages, 2013.

[22] M. Tsutsumi and A. Saito, "Identification and compensation of systematic deviations particular to 5-axis machining centers," International Journal of Machine Tools and Manufacture, vol. 43, no. 8, pp. 771-780, 2003.

[23] T. Huang, Y. Li, G. Tang et al., "Error modeling, sensitivity analysis and assembly process of a class of 3-DOF parallel kinematic machines with parallelogram struts," Science in China, Series E: Technological Sciences, vol. 45, no. 5, pp. 467-476, 2002.

[24] F. Xi, M. Verner, and C. Mechefske, "Error sensitivity analysis for optimal calibration of parallel kinematic machines," in Proceedings of the ASME International Design Engineering Conference, vol. 2, pp. 745-752, 2002.

[25] Y.-J. Liu and S. C. Tong, "Adaptive fuzzy control for a class of nonlinear discrete-time systems with backlash," IEEE Transactions on Fuzzy Systems, vol. 22, no. 5, pp. 1359-1365, 2014.

[26] R. S. Lee and Y. H. Lin, "Applying bidirectional kinematics to assembly error analysis for five-axis machine tools with general orthogonal configuration," International Journal of Advanced Manufacturing Technology, vol. 62, no. 9-12, pp. 1261-1272, 2012.

[27] D. Li, P. Feng, J. Zhang, D. Yu, and Z. Wu, "An identification method for key geometric errors of machine tool based on matrix differential and experimental test," Proceedings of the Institution of Mechanical Engineers, Part C: Journal of Mechanical Engineering Science, vol. 228, no. 17, pp. 3141-3155, 2014.

[28] Q. Cheng, H. Zhao, G. Zhang, P. Gu, and L. Cai, "An analytical approach for crucial geometric errors identification of multiaxis machine tool based on global sensitivity analysis," The International Journal of Advanced Manufacturing Technology, vol. 75, no. 1-4, pp. 107-121, 2014.

[29] G. Chen, Y. Liang, Y. Sun, W. Chen, and B. Wang, "Volumetric error modeling and sensitivity analysis for designing a five-axis ultra-precision machine tool," International Journal of Advanced Manufacturing Technology, vol. 68, no. 9-12, pp. 2525-2534, 2013.

[30] X. Zhang, Y. Zhang, and M. D. Pandey, "Global sensitivity analysis of a CNC machine tool: application of MDRM," The International Journal of Advanced Manufacturing Technology, vol. 81, no. 1, pp. 159-169, 2015.

[31] Y.-J. Liu and S. Tong, "Adaptive fuzzy control for a class of unknown nonlinear dynamical systems," Fuzzy Sets and Systems, vol. 263, pp. 49-70, 2015.

[32] A. Saltelli, S. Tarantola, and K. P.-S. Chan, "A quantitative model-independent method for global sensitivity analysis of model output," Technometrics, vol. 41, no. 1, pp. 39-56, 1999.

[33] K. Fan, J. Yang, and L. Yang, "Unified error model based spatial error compensation for four types of CNC machining center: part II-unified model based spatial error compensation," Mechanical Systems and Signal Processing, vol. 49, no. 1-2, pp. 63-76, 2014.
[34] ISO, "Test code for machine tools-part 1: geometric accuracy of machines operating under no-load or quastic-static conditions," ISO 230-1, ISO Copyright Office, Zurich, Switzerland, 2012.

[35] ISO, "Test conditions for machining centres-part 1: geometric tests for machines with horizontal spindle (horizontal Z-axis)," ISO/DIS 10791-1, ISO Copyright Office, Zurich, Switzerland, 2012.

[36] S. Su, S. Li, and G. Wang, "Identification method for errors of machining center based on volumetric error model," Chinese Journal of Mechanical Engineering, vol. 38, no. 7, pp. 121-127, 2002.

[37] Y. C. Shin and Y. Wei, "A statistical analysis of positional errors of a multiaxis machine tool," Precision Engineering, vol. 14, no. 3, pp. 139-146, 1992.

[38] A. Saltelli and R. Bolado, "An alternative way to compute Fourier amplitude sensitivity test (FAST)," Computational Statistics and Data Analysis, vol. 26, no. 4, pp. 445-460, 1998.

[39] W. L. Feng, X. D. Yao, A. Azamat, and J. G. Yang, "Straightness error compensation for large CNC gantry type milling centers based on B-spline curves modeling," International Journal of Machine Tools and Manufacture, vol. 88, pp. 165-174, 2015.

[40] Y. Gao and Y.-J. Liu, "Adaptive fuzzy optimal control using direct heuristic dynamic programming for chaotic discretetime system," Journal of Vibration and Control, vol. 22, no. 2, pp. 595-603, 2016.

[41] J. Yuan and J. Ni, "The real-time error compensation technique for CNC machining systems," Mechatronics, vol. 8, no. 4, pp. 359-380, 1998.

[42] B. Feng, D. Zhang, J. Yang, and S. Guo, "A novel timevarying friction compensation method for servomechanism," Mathematical Problems in Engineering, vol. 2015, Article ID 269391, 16 pages, 2015. 


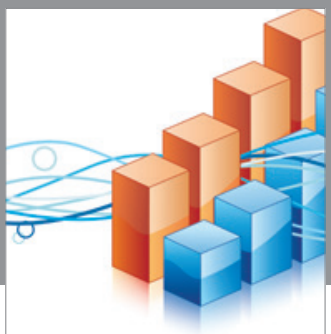

Advances in

Operations Research

vatem alat4

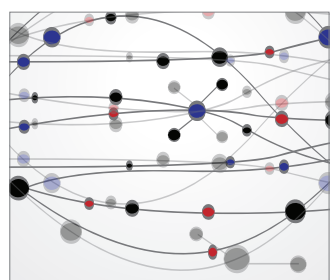

\section{The Scientific} World Journal
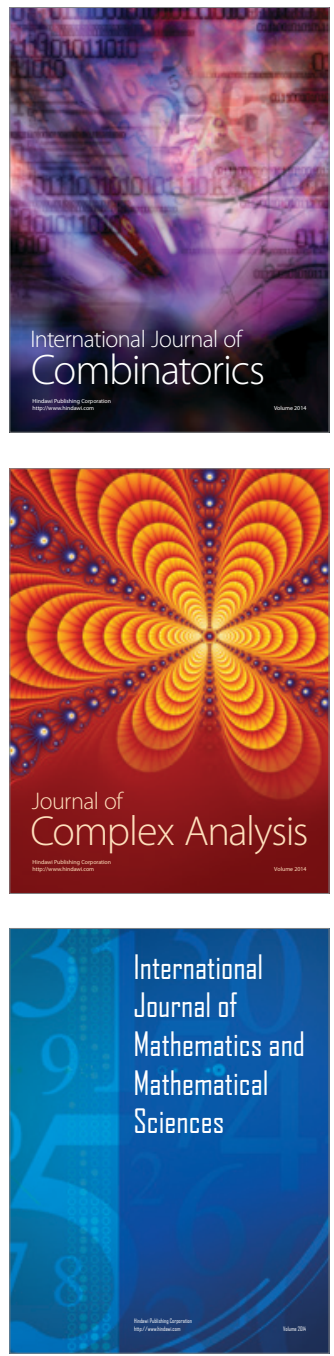
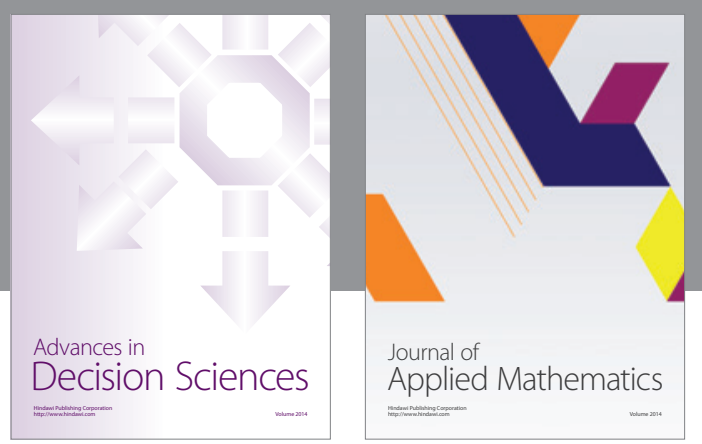

Algebra

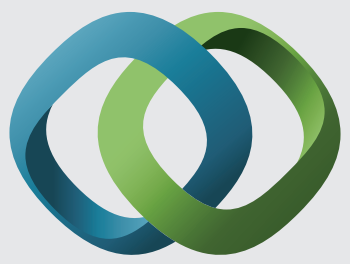

\section{Hindawi}

Submit your manuscripts at

http://www.hindawi.com
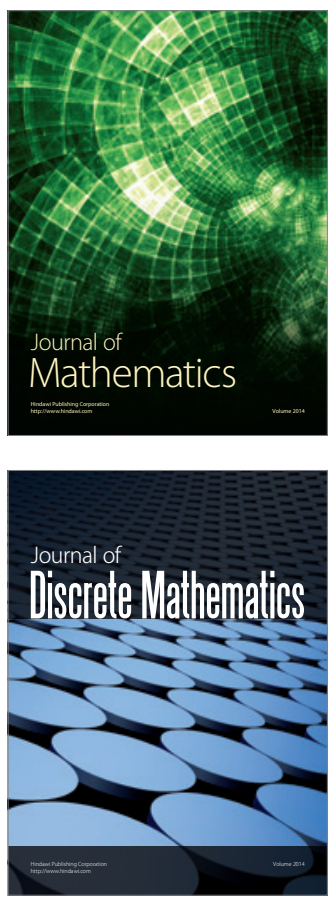

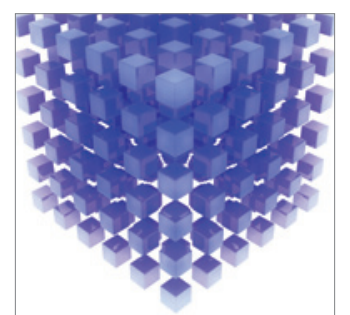

Mathematical Problems in Engineering
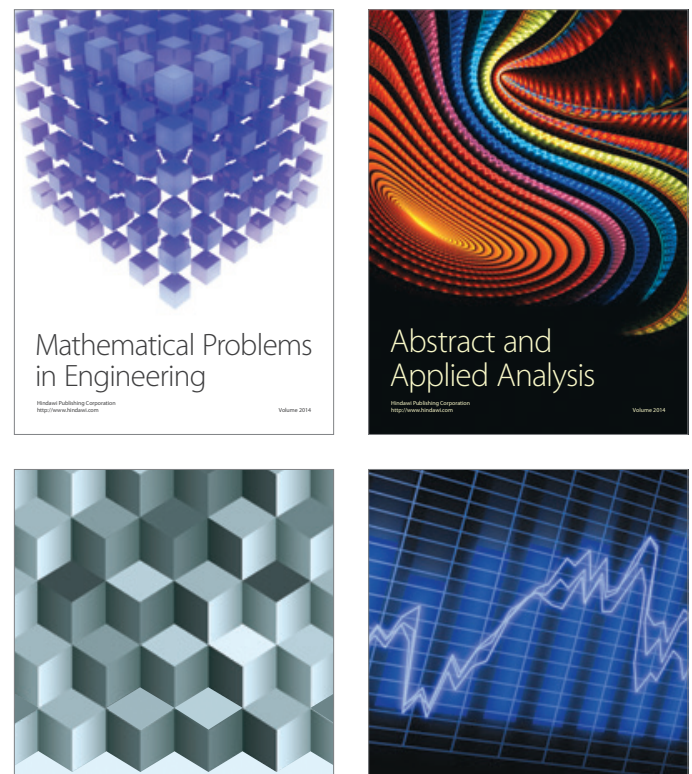

Journal of

Function Spaces

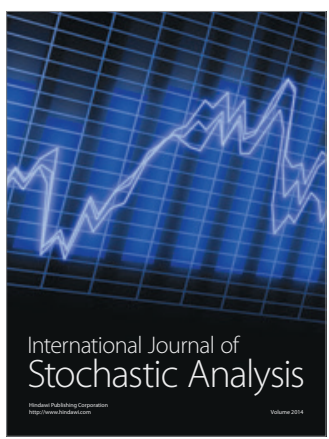

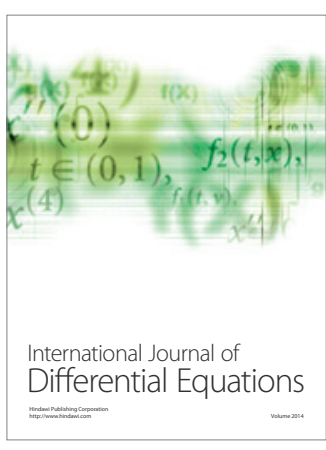
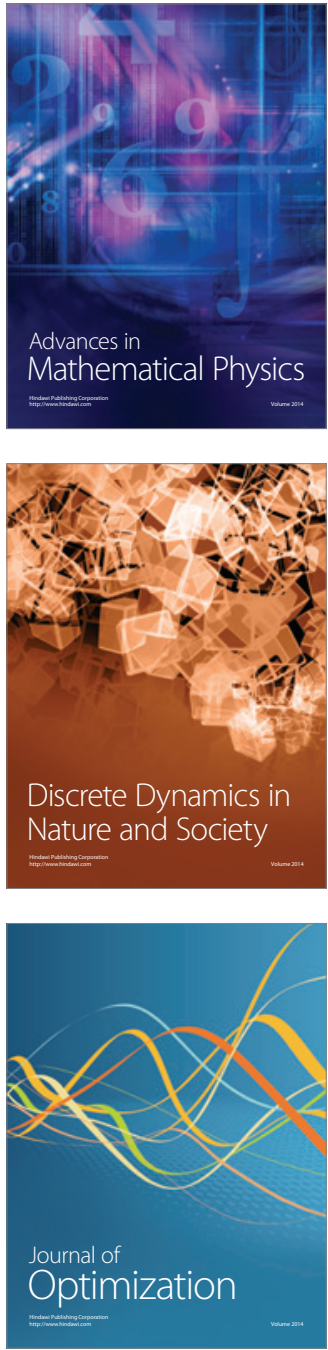